\title{
Die Rezeption der EMRK sowie der Urteile des EGMR in der französischen und deutschen Rechtsprechung
}

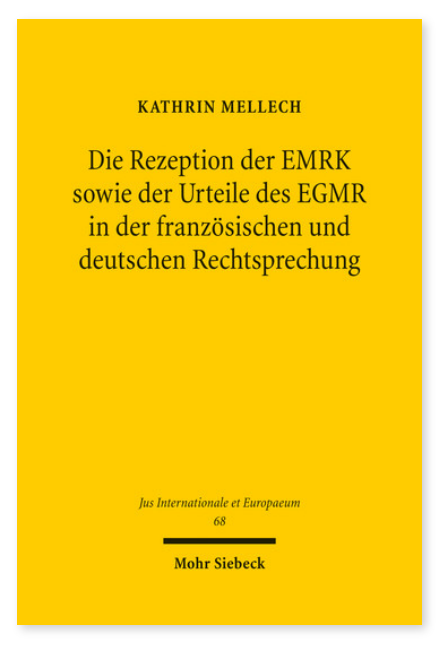

2012. XVII, 270 Seiten. JusIntEu 68

ISBN 978-3-16-152302-1

DOI 10.1628/978-3-16-152302-1

eBook PDF 74,00€

ISBN 978-3-16-151999-4

fadengeheftete Broschur 74,00€
Auf Grund des Erfordernisses der Erschöpfung des innerstaatlichen Rechtsweges ist es zuallererst die Pflicht der nationalen Gerichte, den Konventionsrechten innerstaatliche Geltung zu verleihen. Da es im Interesse eines jeden Staates liegen müsste, eine Verurteilung durch den EGMR zu vermeiden, dürfte eigentlich zu erwarten sein, dass die nationalen Gerichte der Anwendung der EMRK einen hohen Stellenwert einräumen. Angesichts zahlreicher Verurteilungen der Vergleichsstaaten bestehen indes Zweifel, ob die innerstaatliche Rechtsprechung sich ihrer Funktion im europäischen Rechtsschutzsystem hinreichend bewusst ist. Kathrin Mellech untersucht unter Berücksichtigung der strukturellen Unterschiede zwischen französischer und deutscher Rechtsordnung daher insbesondere die Einstellung der innerstaatlichen Rechtsprechung gegenüber dem Konventionsrecht und deren Wandel.

Kathrin Mellech Keine aktuellen Daten verfügbar.

Jetzt bestellen:

https://mohrsiebeck.com/buch/die-rezeption-der-emrk-sowie-der-urteile-des-egmr-in-der-franzoesischen-und-deutschenrechtsprechung-9783161523021?no_cache=1

order@mohrsiebeck.com

Telefon: +49 (0)7071-923-17

Telefax: $+49(0) 7071-51104$ 